ble for him to remain in bed or shut his eyes in sleep for several hours. I proposed opium. To this he strongly objected; said he could not bear it; and that, taken in any quantity whatever, it always kept him awake, and otherwise distressed him. At length, however, I prevailed upon bim to take, half an hour before going to bed, ahout six grains. He immediately fell asleep, and rested quietly till morning; a circumstance which bad not before occurred for weeks together. There was some nausea on rising, the next morning: but it was not considerable.

The pill was repeated-though in diminished quantity, say five grains - the next evening, and with the same success, but with inore nausea the following morning. The third night I gave four grains. The results were the same, except that he vomited the next morning and refused to take any inore medicine. The pain, however, was gone, and did not reappear for several weeks.

It is, perhaps, worthy of remark, that, in the case of this person, and one or two other individuals 1 have met with, the effects of opium, on the bowels, in considerable quantities, are always laxative. I may also add, that I have found some obstinate cases of rheumatism in laborers who were intemperate, which would yield to nothing but opiates. In one, I recollect giving laudanum in doses of half an ounce or more.
Boston, Oct. 5, 1837.
Yours, \&c.
W. A. A.

\title{
a Case of CONGENital OSCILlation OF THE EYE-Balls.
}

BY EDWARD J. DAVENPORT, M.D., BOSTON.

[Communicated for the Boston Medical and Surgical Journal.]

Oscillation of the eye-ball, or a perpetual semi-rotatory motion round its antero-posterior axis, invariably attends congenital cataract, especially if of some years' standing.* It likewise occurs in young children in other diseases of the eye, in which vision is materially and permanently impaired. "It seems to be produced by the antagonizing action of the obliqui, the recti having lost, in a great measure, their control over the eye. The motion varies in extent, from a scarcely perceptible degree, to as much as a fourth of the circuinference of the eye-ball." In the case detailed below (the only one of the kind that has come under my notice), the power of vision is good, and nothing presents itself to explain the occurrence of these diseased motions, except a slight degree of what has been terned morbid sensibility of the retina, or inability in the nervous apparatus of the organ to sustain long-continued application.

The subject of this case is B. Sinith, an intelligent lad of 13 years of age, of good general health and active habits. Complicated with the tremulous oscillating motion, there is a frequent convulsive motion of the eye-ball from side to side-nystagmus of some authors-and also a constant " morbid nictitation," or spasmodic action of the orbicularis palpe-

* Vi. Mackenzie on the Eye. 
brarum. He is not conscious of either motion, nor can he restrain them or $6 \mathbf{x}$ his eyes steadily on any object. Yet such is the force of habit or education, that he possesses perfect command over the muscles of the body, as in walking, running, \&c. The convulsive motions of the eye-ball are evidently aggravated by agitation of mind, when they succeed one another with astonishing rapidity. The eye-balls are well formed, and perfectly free from inflammation. Cornex clear and transparent; anterior chamber and deep-seated hunors in a healthy state; the irides are of a light blue color, with the smaller or internal rings, of an orange; their motions lively, the pupils dilating and contracting, as the quantity of light is diminished or increased, with great quickness and to a remarkable extent. At the same time, when exposed for a while to a moderate degree of light, the pupils seemed rather more dilated than usual in a sound eye. The power of vision is quite suffcient for a moderate application of the eyes, but any long-continued application upon sınall objects, as in reading, occasions a sensation, as expressed by the patient, "as if the objects were moved from the eyes to a great distance ;" or, in other words, vision becomes indistinct.

This patient is not affected with muscæ volitantes, ocular spectra, or double vision, nor any of those states of defective vision usually preceding anuaurosis. Upon inquiry, says he thinks himself sonewhat nearsighted. Has brothers and sisters, whose eyes are perfect in all respects. Says his parents believe that the convulsive motions are gradually diminishing, though very slowly.

No treatment was reconmended, except rest for the eyes, the application of leeches, if pain should occur, and active exercise in the open air, with attention to the state of the general health.

No. 4 Winter Street, Oct., 1837.

BOSTON MEDICAL AND SURGICAL JOURNAL.

BOSTON, OCTOBER 18, J 837 .

\section{FESSENDEN'S STOVES.}

THIs is not the first time we have urged upon our professional brethren the health and economy of this excellent contrivance, which is intended for warming apartments principally by hot water, and may by seen at the Agricultural Warehouse, North Market Street. Wards of hospitals might be made comfortable by these stoves, and we hope to see them introduced into such establishments. In libraries, also, those snug quarters where literary men pass so many hours of the twenty-four, the inmates would have a better colored skin and a much freer pair of lungs, if they would inhale an atmosphere delightfully moistened and tempered by the evaporations of one of these adnirable inventions. The consumption of fuel is small-bearing no ordinary proportion to the dimensions of a room. Water-hot, boiling hot-is necessarily always at hand, which in a family or a public institution, cannot fail of being continually 